\title{
TITLE:
}

\section{$<$ News $>$ Celebrating 50 Years of Chimpanzee Research at Gombe National Park, Tanzania}

$\operatorname{AUTHOR}(S)$ :

Wilson, Michael L.

\section{CITATION:}

Wilson, Michael L.. <News> Celebrating 50 Years of Chimpanzee

Research at Gombe National Park, Tanzania. Pan Africa News 2010, 17(2): 13-15

ISSUE DATE:

2010-12

URL:

http://hdl.handle.net/2433/143523

RIGHT:

Copyright (C) Pan Africa News. 


\section{<NEWS>}

\section{Celebrating 50 Years of} Chimpanzee Research at Gombe National Park, Tanzania

Michael L. Wilson ${ }^{1,2}$

1 Department of Anthropology, University of Minnesota, Minneapolis, USA

2 Department of Ecology, Evolution and Behavior, St. Paul, USA

(E-mail:wilso198@umn.edu)
2010 marks the 50th year of Jane Goodall's study of wild chimpanzees at Gombe National Park, Tanzania. As the first long-term study site for wild chimpanzees, Gombe provided many key insights into the behavior and ecology of chimpanzees, and continues to play a major role in primate studies today. To celebrate the scientific achievements of the Gombe study, and to discuss how Gombe and other long-term studies have helped promote conservation, researchers held two symposia on September 13th, 2010, the first day of the XXIIIrd Congress of the International Primatological Society in Kyoto, Japan. 
The first symposium, titled "Reason for Hope: The Quest for Coexistence Among African Hominoids," was organized by Tetsuro Matsuzawa and Juichi Yamagiwa. Alluding to Jane Goodall's book, Reason for Hope, this symposium broadly addressed the relationship between long-term research and conservation efforts, and also provided valuable historical perspectives. Tetsuro Matsuzawa began the symposium with a talk on efforts to care for and conserve chimpanzees, describing the accomplishments of SAGA (Support for African/Asian Great Apes), including efforts to synthesize field and laboratory studies of chimpanzees, and conservation efforts including the "Green Corridor" reforestation program at Bossou, Guinea'. Next, Juichi Yamagiwa spoke on the unique scope and methodology of Japanese primatology, whose development has been influenced by the long coexistence of people and nonhuman primates in Japan ${ }^{2}$. Yamagiwa noted that Kinji Imanishi, who began studying Japanese macaques in 1948, also pioneered efforts to study African apes, starting in 1958, surveying mountain gorilla habitat together with Junichiro Itani. Despite the various differences between Eastern and Western primatological perspectives, it is interesting to note that at Gombe, Goodall employed some methods that had been used in Japan by Imanishi and his students, including a focus on named individuals and the use of provisioning to speed habituation. In the next talk, Gen'ichi Idani gave an overview of studies of two populations that, compared to chimpanzees in forested areas such as Gombe and Mahale, remain less well understood: bonobos and woodland chimpanzees ${ }^{3}$. Richard Wrangham then spoke on how long-term research has proven to be critically important, both in the protection of specific populations, and in gaining the information, developing the tools, and building the local and international constituencies needed to promote conservation ${ }^{4}$. Wrangham argued that simply maintaining a long-term research site provides important benefits, as keeping staff on the ground helps monitor and deter threats such as poaching and illegal logging, and employing local people helps create a local constituency for protecting the site. Moreover, many field scientists have now taken an active role in promoting conservation outreach, ecotourism, and actively use the research findings and images from their studies to help create international constituencies for conservation.

Jane Goodall, who has for many years worked to create such international constituencies for Gombe, for all chimpanzees, and for wildlife in general, gave the concluding talk of the first symposium, describing her own reasons for hope ${ }^{5}$. When Goodall first arrived at Gombe on 14 July 1960, her mentor, Louis Leakey, had secured funding for a four-month study, which would be nearly twice as long as any previous effort to study chimpanzees in the wild. Goodall quickly realized, however, that even four months would not be sufficient to fully understand the complex lives of chimpanzees. Goodall described how as she worked to make Gombe a long-term study, the small operation begun with a single researcher living in a tent developed into Gombe Stream Research Centre, with a staff of researchers studying three chimpanzee communities plus several baboon troops. After years of struggling to keep the study going, Goodall founded the Jane Goodall Institute (JGI), which not only supports Gombe research but also has become a conservation and education organization operating on a global scale. Goodall described how after five decades of study, with our understanding of chimpanzees enriched by long-term studies such as Mahale, Bossou, Taï, Kibale, and Budongo, as well as a growing number of other sites across Africa, we continue to learn new and surprising things about our chimpanzee cousins. During this time, a rapidly expanding human population has increasingly threatened the continued existence, not just of chimpanzees, but also of many thousands of other species and their habitats around the world. When Goodall began her study, forest and woodland covered most of the steep slopes on the village land surrounding Gombe. During the following five decades, people living in rapidly growing villages cleared much of the former tree cover for farmland, resulting in Gombe becoming increasingly isolated from other chimpanzee populations - and also in the erosion of soil on steep slopes and the degradation of other resources that people need, including clean water and firewood. Gombe thus emphatically demonstrates the challenges facing conservation, as well as the importance of conservation for human welfare. Goodall reported reasons that, despite these many challenges, she remains hopeful. The former Game Reserve, now Gombe National Park, benefits from efforts by JGI to promote reforestation in the Greater Gombe Ecosystem. On a global scale, Goodall described the eagerness to help the environment that she regularly encounters when talking to young people.

The second symposium, "Fifty years of primate research at Gombe National Park, Tanzania," organized by Anne Pusey and myself, highlighted recent scientific findings. I began the symposium with a talk on the causes of intergroup aggression ${ }^{6}$, presenting results from 35 years of data on how ecological factors, especially the abundance of key species of ripe fruit, affect the probability of intergroup interactions. Lilian Pintea followed with a talk examining how grouping patterns in border areas change as power relations among chimpanzee communities change ${ }^{7}$. This study used both behavioral data and remote sensing data, to test whether habitat quality affected party composition. Ian Gilby presented findings from a study of whether dominance style affects reproductive success of alpha males ${ }^{8}$, a study which followed in the tradition of Goodall's emphasis of the importance of each individual. This study also made use of new data on paternities obtained by the next speaker, Emily Wroblewski, who has conducted extensive lab work on genetics in addition to behavioral observations in the field. Wroblewski gave a talk on how fathers interact with their offspring ${ }^{9}$. Because Anne Pusey was unable to attend the conference, Ian Gilby presented Pusey's talk on factors affecting sexual cycles in chimpanzees ${ }^{10}$. Two talks from Gombe researchers based at Lincoln Park Zoo, Chicago, examined different aspects of chimpanzee health and wellbeing. Carson Murray presented results from her study of maternal behavior and stress, as measured from fecal hormones ${ }^{11}$, and Elizabeth Lonsdorf provided an 
overview of the impact of disease on the population $^{12}$. In addition to chimpanzees, Gombe is also the site of one of the longest running studies of baboons, which were represented in this symposium by Akiko Matsumata-Oda's talk on oestrus asynchrony in baboons ${ }^{13}$. Finally, drawing connections between this symposium and the previous one, Shadrack Kamenya presented a talk on conservation in the Greater Gombe Ecosystem ${ }^{14}$.

Together, these talks showcased the value of long-term behavioral and ecological data. Because chimpanzees live long lives, reproduce slowly, and live in complex environments that change greatly from year to year depending on fluctuations in rainfall and the fruiting patterns of key food species, long-term data are essential for understanding

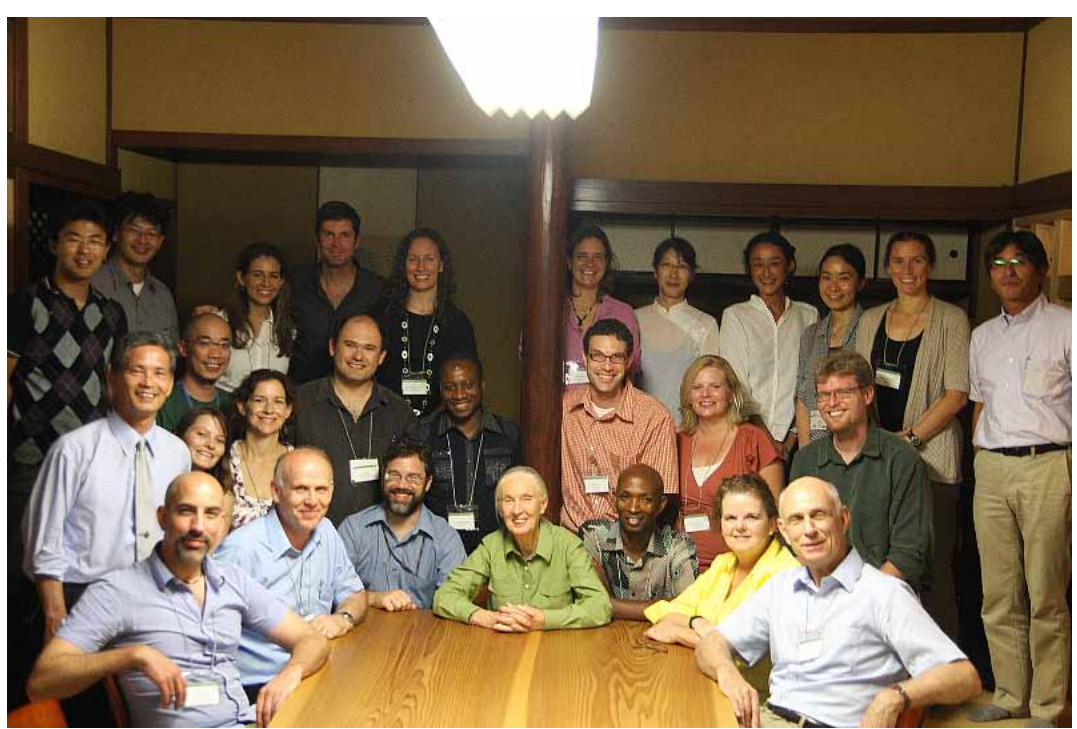

Soiree at Yoshida-Izumidono chimpanzee behavior and ecology. Such large datasets, however, present an imposing obstacle for analysis, unless the data are computerized. Most of the findings reported in the symposium relied on the relational database that Anne Pusey and colleagues have developed from the long-term records. Additionally, many of the talks combined analyses of these long-term data with information available from new technologies on a range of scales, from the molecular (genetics, endocrinology, virology) and microscopic (parasitology) to landscapes (GIS and remote sensing). The findings presented in this symposium demonstrated how long-term datasets, focused on the behavior of individuals, yet also probing for data on scales large and small, provide powerful tools for answering key scientific questions.

Following the two symposia, Tetsuro Matsuzawa hosted a soiree for Jane Goodall, current and former Gombe researchers, and other friends of Gombe at Yoshida-Izumidono.

\section{REFERENCES}

The following are all talks given at the XXIII Congress of the International Primatological Society, Kyoto, Japan, 12-18 September, 2010. Abstracts of these talks are available at http://wwwsoc.nii.ac.jp/psj2/ips/:

1. Matsuzawa T 2010. Support for African/Asian Great Apes (SAGA): Efforts toward the care and conservation of chimpanzees.

2. Yamagiwa J 2010. Japanese primatology: Its unique scope and methodology.

3. Idani G 2010. From the bonobos' forest to the chimpanzees' woodland.

4. Wrangham RW, Ross E, Lloyd J, Pokempner AA 2010. Impacts of long-term research on conservation.

5. Goodall J 2010. My reasons for hope: What I learned from Gombe 50 Years.

6. Wilson ML, Mjungu DC, Pusey AE 2010. Causes of intergroup aggression among chimpanzees at Gombe.

7. Pintea L, Wilson ML, Gilby IC, Pusey AE 2010. Power relations among neighboring communities affect party size and composition in Gombe chimpanzees: A remote sensing and GIS analysis.

8. Gilby IC 2010. Alpha male chimpanzees at Gombe: Consequences of dominance style.
9. Wroblewski EE, Johnson L, Murray CM, Henderson J, Stanley A, Pusey AE 2010. Father-offspring relations among the Gombe chimpanzees (Pan troglodytes schweinfurthii).

10. Pusey AE 2010. Factors influencing number of sexual cycles in the Gombe chimpanzees.

11. Murray CM, Heintz MR, Santymire RM, Lipende I, Lonsdorf EV 2010. Stress and maternal behavior in wild chimpanzees at Gombe National Park, Tanzania.

12. Lonsdorf EV, Travis DA, Lipende I, Murray CM, Raphael J, Lonsdorf EV, Gilby IC, Gillespie TR, Terio KA, Kinsel MJ, Chosy J, Rudicell R, Hahn BH, Pusey AE, Goodall J 2010. The impact of disease on the Gombe chimpanzeespast and present.

13. Matsumoto-Oda A, Ihara Y, Oda R, Collins DA 2010. Female baboons adopt a mate strategy of oestrus asynchrony in Gombe.

14. Kamenya SM, Pintea L, Mtiti ER, Ndimuligo SA 2010. Conserving the Greater Gombe Ecosystem. 